Article

\title{
Simultaneous Analysis of Irbesartan and Hydrochlorothiazide: An Improved HPLC Method with the Aid of a Chemometric Protocol
}

\author{
Zorica Vujić $^{1, *}$, Nedžad Mulavdić ${ }^{2}$, Miralem Smajić ${ }^{2}$, Jasmina Brborić ${ }^{1}$ and \\ Predrag Stankovic ${ }^{3}$
}

1 Institute for Pharmaceutical Chemistry, University of Belgrade-Faculty of Pharmacy, Vojvode Stepe 450, 11000 Belgrade, Serbia; E-Mail: jbrboric@pharmacy.bg.ac.rs

2 Institute for Pharmaceutical Chemistry, University of Tuzla-Faculty of Pharmacy, Univerzitetska 8, 18000 Tuzla, Bosnia and Herzegovina; E-Mails: Nedzadmulavdic@yahoo.com (N.M.); smajic.m@hotmail.com (M.S.)

3 Institute of Otorhinolaryngology, Clinical Centre of Serbia, Pasterova 2, 11000 Belgrade, Serbia; E-Mail: stankovic.pms@sezampro.rs

* Author to whom correspondence should be addressed; E-Mail: zvujic@pharmacy.bg.ac.rs; Tel.: +381-11-39-51-340; Fax: +381-11-29-72-840.

Received: 23 February 2012; in revised form: 12 March 2012 / Accepted: 13 March 2012 / Published: 16 March 2012

\begin{abstract}
Experimental design method was used for HPLC determination of irbesartan and hydrochlorothiazide in combined dosage forms. The traditional approach for optimization of experiments is time-consuming, involves a large number of runs and does not allow establishing the multiple interacting parameters. The main advantages of the experimental design method include the simultaneous screening of a larger number of factors affecting response and the estimation of possible interactions. On the basis of preliminary experiments, three factors-independent variables were selected as inputs (methanol content, $\mathrm{pH}$ of the mobile phase and temperature) and as dependent variables, five responses (resolution, symmetry of irbesartan peak, symmetry of hydrochlorothiazide peak, retention factor of irbesartan and retention factor of hydrochlorothiazide) were chosen. A full $2^{3}$ factorial design, where factors were examined at two different levels ("low" and "high") was used to determine which factors had an effect on the studied response. Afterwards, experimental design was used to optimize these influent parameters in the previously selected experimental domain. The novelty of our method lies in the optimization step accomplished by Derringer's desirability function. After optimizing the
\end{abstract}


experimental conditions a separation was conducted on a Supelcosil $\mathrm{C}_{18}(150 \mathrm{~mm} \times 4.6 \mathrm{~mm}$, $5 \mu \mathrm{m}$ particle size) column with a mobile phase consisting of methanol-tetrahydrofuranacetate buffer 47:10:43 v/v/v, pH 6.5 and a column temperature of $25{ }^{\circ} \mathrm{C}$. The developed method was successfully applied to the simultaneous separation of these drug-active compounds in their commercial pharmaceutical dosage forms.

Keywords: HPLC; experimental design; irbesartan; hydrochlorothiazide

\section{Introduction}

Irbesartan [IRB, 2-butyl-3-[[2'-(1H-tetrazol-5-yl)[1,1'-biphenyl]-4-yl]- methyl1-3-diazaspiro-[4,4]non-1-en-4-one, Figure 1(a)] is an angiotensin II blocker. Angiotensin II receptor antagonists represent a relatively new pharmacological class [1] which acts mainly by selective blockade of AT1 receptors and reduces the effects of angiotensin II. They may be used alone or in combination with other antihypertensive or diuretic agents. Hydrochlorothiazide [HCT, 6-chloro-3,4-dihydro-2H-1,2,4benzothiadiazine-7-sulphonamide-1,1-dioxide, Figure 1(b)] is a diuretic acting on distal convoluted tubule. Because of their synergistic anti-hypertensive action, irbesartan and hydrochlorothiazide are available on the market as a combined dosage form.

Figure 1. Structural formulae of irbesartan (a) and hydrochlorothiazide (b).
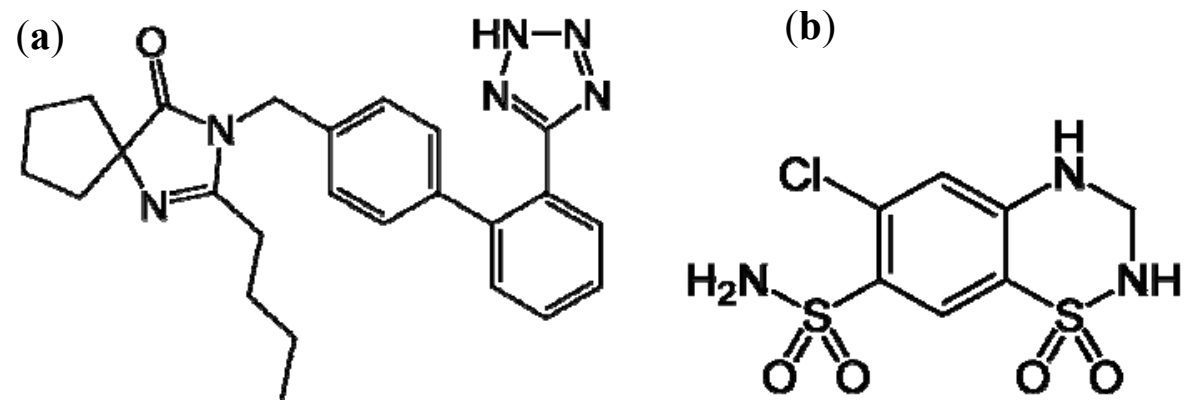

A literature survey revealed that there are a number of HPTLC [2-5], spectrophotometric [6], and spectrofluorometric [7,8], voltammetric [9], capillary zone electrophoretic [10], HPLC [11,12] and LC-MS $[13,14]$ methods for determination of the individual drugs (IRB and HCT) or IRB/HCT in combination with other drugs. Although a number of methods for the determination of irbesartan and hydrochlorothiazide have been reported, there are a limited number of systematic studies for the optimization of separation parameters.

Some published papers have dealt with the optimization procedure for determination either of IRB (and other angiotensin-II-receptor antagonist) [15-18] or HCT [19,20], but to the best of our knowledge neither of the already published methods has been related to HPLC method optimization for simultaneous determination of IRB and HCT. The aim of this work was the evaluation of the chromatographic behavior of IRB and HCT using an appropriate experimental design (ED). The main advantage of such approach is simultaneous optimization of influencing factors and response variables 
which enables prediction of chromatographic retention and postulation of optimum conditions for separation.

Several statistical approaches could be used for estimating the retention behavior as a function of chromatographic conditions. In this work, full factorial design (FFD) and response surface methodology (RSM) have been applied. Factorial design enables an estimation of investigated factors which have the most importance. Response surface methodology is generally employed in order to provide a description of the response pattern in the region of the studied observations and to assist in finding the region where the optimal response occurs [21].

Marketed tablet formulation (Co-Irda tablets, Nobel Ilac, Turkey) containing $150 \mathrm{mg}$ of irbesartan and $12.5 \mathrm{mg}$ of hydrochlorthiazide have been analyzed. The significant feature of this combination lies in the fact that hydrochlorthiazide is present in minute amounts compared to irbesartan, which makes an analysis more complicated and tedious. In the present paper, a fast, simple and accurate HPLC method has been proposed without the tedious extraction procedure.

\section{Results and Discussion}

When applying experimental design methodologies, it is advisable to keep the number of variables as low as possible in order to avoid very complex response models and large variability. When the number of influencing factors is up to four, full factorial design (FFD) is recommended.

The investigation was carried out in several steps. The objective of the first step in the investigation was to perform a screening of the factors that could potentially influence chromatographic retention, thus the independent variables were defined during the preliminary study. Some chromatographic parameters, such as flow rate were excluded as its influence can usually be predicted by common chromatographic theory knowledge. The factors generally selected to optimize the chromatographic separation of ionisable compounds are $\mathrm{pH}$ and the content of organic solvent of the mobile phase. The variations of these parameters induce a variation of the degree of ionization and thus affect chromatographic behavior. In addition, column temperature affects retention behavior, thus three factors-independent variables were selected as inputs: methanol content, $\mathrm{pH}$ of the mobile phase and temperature. Since a good separation is characterized by good resolution and since run time is very important (from a practical point of view), five responses were chosen as dependent variables: resolution $\left(\mathrm{k}_{\mathrm{R}}\right)$, symmetry of the irbesartan peak $\left(\mathrm{Sym}_{\mathrm{IRB}}\right)$, symmetry of the hydrochlorothiazide peak $\left(\mathrm{Sym}_{\mathrm{HCT}}\right)$, retention factor of irbesartan $\left(\mathrm{Rt}_{\mathrm{IRB}}\right)$ and retention factor of hydrochlorothiazide $\left(\mathrm{Rt}_{\mathrm{HCT}}\right)$.

The presence of several functional groups in the molecular structures, such as biphenyl, imidazole and benzene (Figure 1), makes a RP-HPLC method with PDA detection suitable for the determination. Since the RP-HPLC method is based on using a polar mobile phase, a complete description of the ionization profile of the examined substances has been used for the evaluation of retention behavior and also for the separation. The degree of ionization of the drug strongly affects solubility and retention. Additionally, the knowledge of dissociation constant of ionisable compounds at different $\mathrm{pH}$ values and the solvent composition is also significant to determine the optimal separation conditions in reversed phase liquid chromatography (RP-LC). Considering the chemical structures, it is possible to establish a number of proton acceptor and donor groups (Figure 2), to assume ionized structures of IRB and HCT (Figures 3 and 4) and degrees of ionization depending on the pH (Tables 1 and 2). 
Figure 2. Proton acceptor (A) and donor groups (D) of IRB and HCT at $\mathrm{pH} 4(\mathbf{a}, \mathbf{c})$ and $\mathrm{pH} 6(\mathbf{b}, \mathbf{d})$.

(a)<smiles>CCCCC1=NC2(CCCC2)C(=O)N1Cc1ccc(-c2ccccc2-c2nn[nH]n2)cc1</smiles>

(b)<smiles>CCCCC1=NC2(CCCC2)C(=O)N1Cc1ccc(-c2ccccc2-c2nn[nH]n2)cc1</smiles>

(c)<smiles>NS(=O)(=O)c1cc2c(cc1Cl)NCNS2(=O)=O</smiles>

(d)<smiles>NS(=O)(=O)c1cc2c(cc1Cl)NCNS2(=O)=O</smiles>

Figure 3. Structural formulae of ionized IRB.
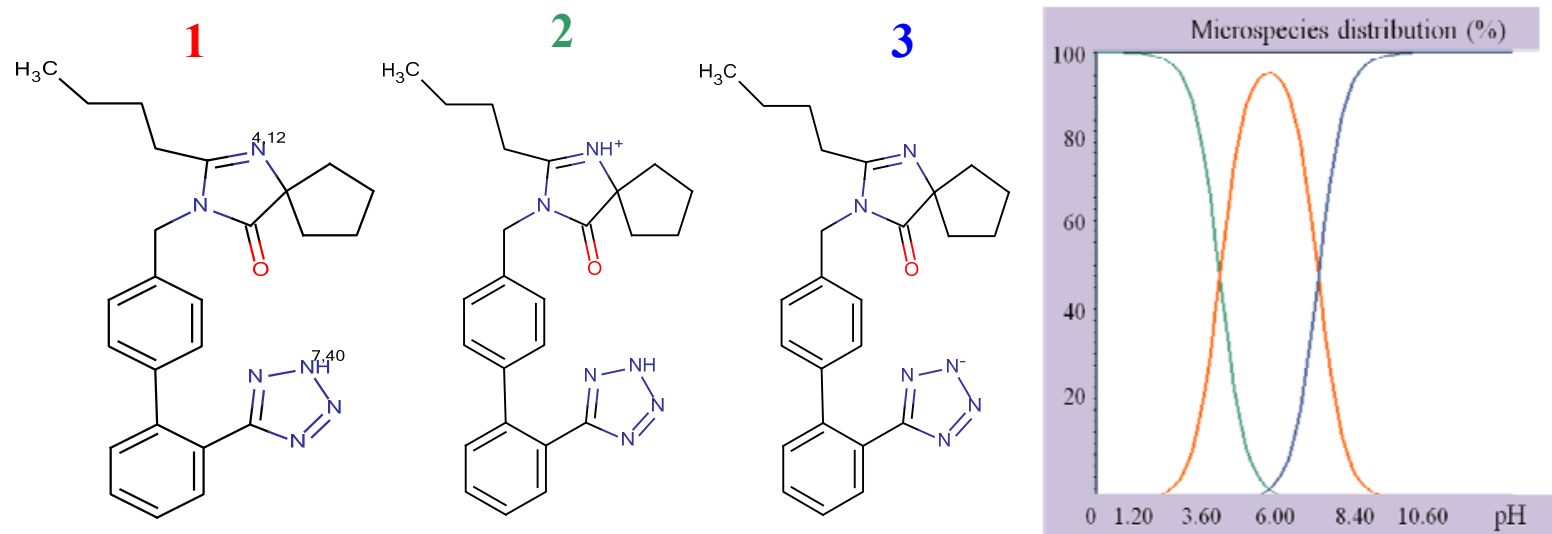

Figure 4. Structural formulae of ionized HCT.<smiles>NS(=O)(=O)c1cc2c(cc1Cl)NCNS2(=O)=O</smiles><smiles>NS(=O)(=O)c1cc2c(cc1Cl)NCNS2(=O)=O</smiles><smiles>NS(=O)(=O)c1cc2c(cc1Cl)NCNS2(=O)=O</smiles>

4<smiles>NS(=O)(=O)c1cc2c(cc1Cl)NCNS2(=O)=O</smiles><smiles>NS(=O)(=O)c1cc2c(cc1Cl)NCNS2(=O)=O</smiles><smiles>[NH-]S(=O)(=O)c1cc2c(cc1Cl)NCNS2(=O)=O</smiles>

7<smiles>NS(=O)(=O)c1cc2c(cc1Cl)[N-]CNS2(=O)=O</smiles><smiles>NS(=O)(=O)c1cc2c(cc1Cl)NCNS2(=O)=O</smiles>

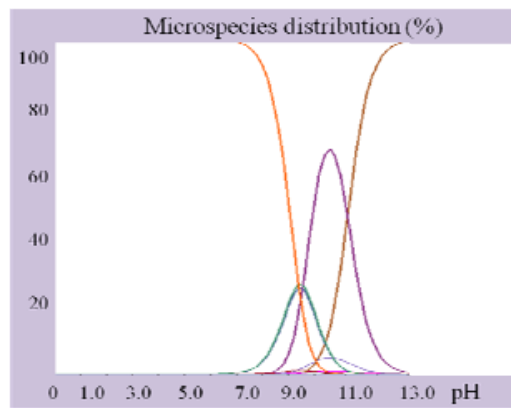


Table 1. Percentage of ionization of IRB depending on $\mathrm{pH}$.

\begin{tabular}{cccccccccccc}
\hline $\mathbf{p H}$ & $\mathbf{1}$ & $\mathbf{2}$ & $\mathbf{3}$ & $\mathbf{4}$ & $\mathbf{5}$ & $\mathbf{6}$ & $\mathbf{7}$ & $\mathbf{8}$ & $\mathbf{9}$ & $\mathbf{1 0}$ & $\mathbf{1 1}$ \\
\hline$\%-1$ & 0.08 & 0.76 & 7.11 & 43.34 & 88.12 & 94.96 & 71.43 & 20.05 & 2.45 & 0.25 & 0.03 \\
$\%-2$ & 99.92 & 99.24 & 92.89 & 56.64 & 11.52 & 1.24 & 0.09 & 0 & 0 & 0 & 0 \\
$\%-3$ & 0 & 0 & 0 & 0.02 & 0.35 & 3.79 & 28.47 & 79.94 & 97.55 & 99.75 & 99.97 \\
\hline
\end{tabular}

Table 2. Percentage of ionization of HCT depending on $\mathrm{pH}$.

\begin{tabular}{cccccccccccccc}
\hline $\mathbf{p H}$ & $\mathbf{1}$ & $\mathbf{2}$ & $\mathbf{3}$ & $\mathbf{4}$ & $\mathbf{5}$ & $\mathbf{6}$ & $\mathbf{7}$ & $\mathbf{8}$ & $\mathbf{9}$ & $\mathbf{1 0}$ & $\mathbf{1 1}$ & $\mathbf{1 2}$ & $\mathbf{1 3}$ \\
\hline$\%-1$ & 100 & 100 & 100 & 100 & 99.99 & 99.92 & 99.19 & 92.33 & 51.53 & 4.55 & 0.05 & 0 & 0 \\
$\%-2$ & 0 & 0 & 0 & 0 & 0 & 0.04 & 0.41 & 3.78 & 21.11 & 18.65 & 2.16 & 0.06 & 0 \\
$\%-3$ & 0 & 0 & 0 & 0 & 0 & 0.04 & 0.39 & 3.62 & 20.21 & 17.85 & 2.07 & 0.05 & 0 \\
$\%-4$ & 0 & 0 & 0 & 0 & 0 & 0 & 0.02 & 0.15 & 0.84 & 0.74 & 0.09 & 0 & 0 \\
$\%-5$ & 0 & 0 & 0 & 0 & 0 & 0 & 0 & 0.1 & 5.78 & 51.04 & 59.03 & 15.56 & 1.84 \\
$\%-6$ & 0 & 0 & 0 & 0 & 0 & 0 & 0 & 0 & 0.08 & 0.74 & 0.86 & 0.23 & 0.03 \\
$\%-7$ & 0 & 0 & 0 & 0 & 0 & 0 & 0 & 0.01 & 0.42 & 3.70 & 4.28 & 1.13 & 0.13 \\
$\%-8$ & 0 & 0 & 0 & 0 & 0 & 0 & 0 & 0 & 0.03 & 2.72 & 31.47 & 82.97 & 98 \\
\hline
\end{tabular}

As it can be seen, IRB has two pKa values (4.12, imidazole nitrogen; 7.40, tetrazole nitrogen) and at $\mathrm{pH} 4$ it is present as a mixture of molecular (43.34\%) and monoprotonated (56.64\%) forms. The structure of HCT has three pKa values (9.09, sulphonamide group; 9.83 cyclic sulphonamide; 11.31, secondary amine). At higher $\mathrm{pH}$ values, HCT is present as a mixture of different deprotonated species. Having in mind the acid-base properties of IRB and HCT, the $\mathrm{pH}$ interval from 4.0 to 6.5 was chosen for further investigation. In this $\mathrm{pH}$ interval, IRB is partially ionized and HCT is completely unionized and under these conditions the following order of retention could be expected: HCT, then IRB. The retention of a substance is a function of the volume fraction of the organic modifier in the mobile phase. Taking into account the variation of the retention factors of compounds with polarity of the mobile phase, a range of methanol concentrations from $35 \%$ to $55 \%$ was selected for investigation.

The analysis of IRB and HCT was started on a non-polar stationary phase (Supelcosil $\mathrm{C}_{18}$ column, $150 \mathrm{~mm} \times 4.6 \mathrm{~mm}, 5 \mu \mathrm{m}$ particle size) with the mobile phase consisting of methanol-tetrahydrofuranacetate buffer ( $\mathrm{pH}$ of mobile phase was adjusted to 4 with acetic acid). The column temperature was set at $35{ }^{\circ} \mathrm{C}$ and the flow rate at $0.75 \mathrm{~mL} / \mathrm{min}$. Acceptable separation was achieved with methanoltetrahydrofuran-acetate buffer mixtures ranging from 35:10:55 to 55:10:35 (v/v/v), but peak shape and run time needed to be improved. In order to evaluate the effect of the most important factor, a $2^{3}$ full factorial design (FFD) with three replicates at the zero level was chosen. The experimental data was coded in order to follow the significance of factors in an easier way. Factors and their "low" $(-1)$, "high" $(+1)$ and "zero" (0) values are presented in Table 3.

Table 3. Factors and levels.

\begin{tabular}{lllll}
\hline \multirow{2}{*}{ Factors } & \multicolumn{3}{c}{ Factor levels } \\
\cline { 3 - 5 } & $(-)$ & $(+)$ & $(0)$ \\
\hline $\mathrm{A}$ & $\mathrm{CH}_{3} \mathrm{OH}$ & 35 & 55 & 45 \\
$\mathrm{~B}$ & $\mathrm{pH}$ of mobile phase & 4.0 & 6.5 & 6.0 \\
$\mathrm{C}$ & $\mathrm{T}\left({ }^{\circ} \mathrm{C}\right)$ & 25 & 50 & 35 \\
\hline
\end{tabular}


A two-level factorial design runs and three replicates of the central point needed 11 runs to complete a whole factorial design. As dependent variables, five responses were chosen: Resolution $\left(\mathrm{k}_{\mathrm{R}}\right)$, symmetry of irbesartan peak $\left(\mathrm{Sym}_{\mathrm{IRB}}\right)$, symmetry of hydrochlorothiazide peak (Sym $\left.\mathrm{HCT}\right)$, retention factor of irbesartan $\left(\mathrm{Rt}_{\mathrm{IRB}}\right)$ and retention factor of hydrochlorothiazide $\left(\mathrm{Rt}_{\mathrm{HCT}}\right)$. The matrix of experiments and results obtained as an average value of three runs are presented in Table 4.

Table 4. Factorial design matrix and results of experiments.

\begin{tabular}{cccccccc}
\hline \multicolumn{3}{c}{ Factors } & \multicolumn{5}{c}{ Results } \\
\hline $\mathbf{A}$ & $\mathbf{B}$ & $\mathbf{C}$ & $\mathbf{k}_{\mathbf{R}}$ & $\mathbf{S y m}_{\mathbf{I R B}}$ & $\mathbf{S y m}_{\mathbf{H C T}}$ & $\mathbf{R t}_{\mathbf{I R B}}$ & $\mathbf{R t}_{\mathbf{H C T}}$ \\
\hline 1 & -1 & -1 & 7.11 & 1.08 & 1.24 & 3.727 & 2.355 \\
-1 & -1 & 1 & 25.2 & 0.97 & 1.21 & 9.762 & 2.48 \\
0 & 0 & 0 & 5.14 & 1.26 & 1.26 & 3.312 & 2.412 \\
-1 & -1 & -1 & 27.56 & 0.97 & 1.53 & 14.567 & 2.79 \\
1 & -1 & 1 & 5.8 & 1.13 & 1.29 & 3.225 & 2.258 \\
0 & 0 & 0 & 5.95 & 1.28 & 1.28 & 3.68 & 2.53 \\
0 & 0 & 0 & 5.33 & 1.28 & 1.29 & 3.447 & 2.49 \\
1 & 1 & 1 & 2.52 & 1.48 & 1.3 & 2.605 & 2.263 \\
1 & 1 & -1 & 2.65 & 1.21 & 1.31 & 2.847 & 2.37 \\
-1 & 1 & 1 & 11.56 & 1.49 & 1.2 & 5.352 & 2.51 \\
-1 & 1 & -1 & 14.68 & 1.52 & 1.46 & 8.145 & 2.867 \\
\hline
\end{tabular}

Appropriate calculations were done with the Design-Expert 7.0 software (Stat-Ease Inc. Minneapolis, MN, USA). A second-order interaction model was suggested as a model of relationship between input and output and is presented by Equation (1):

$$
\mathrm{y}=\mathrm{b}_{0}+\mathrm{b}_{1} \mathrm{~A}+\mathrm{b}_{2} \mathrm{~B}+\mathrm{b}_{3} \mathrm{C}+\mathrm{b}_{12} \mathrm{AB}+\mathrm{b}_{13} \mathrm{AC}+\mathrm{b}_{23} \mathrm{BC}+\mathrm{b}_{123} \mathrm{ABC}
$$

where $b_{0}$ is the intercept, $b_{i}\left(b_{1}, b_{2}, b_{3}\right), b_{i j}\left(b_{12}, b_{13}, b_{23}\right)$ and $b_{i j k}$ represent the regression coefficient and $A, B, C$ represent independent variables. The calculated coefficient and model of polynomial regression is presented in Table 5.

Table 5. Model of coefficients.

\begin{tabular}{ccccccccc}
\hline & $\mathbf{b}_{\mathbf{0}}$ & $\mathbf{b}_{\mathbf{1}}$ & $\mathbf{b}_{\mathbf{2}}$ & $\mathbf{b}_{\mathbf{3}}$ & $\mathbf{b}_{\mathbf{1 2}}$ & $\mathbf{b}_{\mathbf{1 3}}$ & $\mathbf{b}_{\mathbf{2 3}}$ & $\mathbf{b}_{\mathbf{1 2 3}}$ \\
\hline $\mathrm{k}_{\mathrm{R}}$ & 12.14 & -7.62 & -4.28 & -0.87 & 2.35 & 0.51 & 0.052 & 0.24 \\
$\mathrm{Sym}_{\mathrm{IRB}}$ & 1.23 & -0.006 & 0.19 & 0.036 & -0.074 & 0.044 & 0.024 & 0.031 \\
Sym $_{\mathrm{HCT}}$ & 1.32 & -0.032 & 0 & -0.068 & 0.02 & 0.078 & 0 & -0.015 \\
$\mathrm{Rt}_{\mathrm{IRB}}$ & 6.28 & -3.18 & -1.54 & -1.04 & 1.17 & 0.86 & 0.28 & -0.22 \\
$\mathrm{Rt}_{\mathrm{HCT}}$ & 2.49 & -0.18 & 0.016 & -0.11 & -0.011 & 0.058 & -0.007 & 0.0046 \\
\hline
\end{tabular}

The repetition of the central experimental point provided a precise estimation of the experimental errors and the measure of the adequacy of the models (lack of fit). The results were analysed by ANOVA method and the results are presented in Table 6.

The lack of fit test was determined by performing Fischer-F test. The high value of $F$ with a very low probability (only model terms with corresponding $p$-value lesser than 0.05 are significant at $95 \%$ confindence level) implies that there was no evidence of the models lack-of-fit and the models could be accepted as an adequate representation of the data. In addition, the values of $\mathrm{R}^{2}$ and $\mathrm{R}^{2}$ adjusted 
taking into account the degrees of freedom indicated that the regression model fits the data well. The exception is a model which considers the retention time of HCT. Since $p$ is greater than 0.05 , the model needs reduction in order to improve the relationship between parameters.

Table 6. Statistical parameters of models obtained by ANOVA.

\begin{tabular}{ccccccc}
\hline & $\boldsymbol{S S}_{\text {models }}$ & $\boldsymbol{S S}_{\text {models } / \text { df }}$ & $\boldsymbol{F}$ & $\boldsymbol{p}$ & $\boldsymbol{R}^{\mathbf{2}}$ & $\boldsymbol{R}_{\text {adj }}^{2}$ \\
\hline $\mathrm{k}_{\mathrm{R}}$ & 663.23 & 94.75 & 537.93 & 0.0019 & 0.9995 & 0.9976 \\
$\mathrm{Sym}_{\mathrm{IRB}}$ & 0.38 & 0.055 & 409.59 & 0.0024 & 0.9993 & 0.9969 \\
$\mathrm{Sym}_{\mathrm{HCT}}$ & 0.098 & 0.014 & 59.97 & 0.0165 & 0.9953 & 0.9787 \\
$\mathrm{Rt}_{\mathrm{IRB}}$ & 126.28 & 18.04 & 520.54 & 0.0019 & 0.9995 & 0.9975 \\
$\mathrm{Rt}_{\mathrm{HCT}}$ & 0.37 & 0.053 & 14.70 & 0.0652 & Not significant \\
\hline
\end{tabular}

The data collected from the performed FFD design led to the following conclusions: it was noticed that methanol content in the mobile phase and $\mathrm{pH}$ have the largest influence on $\mathrm{k}_{\mathrm{R}}, \mathrm{Rt}_{\mathrm{IRB}}$ and less influence on the other responses. This influence had a minus sign, which means that the higher $\mathrm{pH}$ values and percentage of methanol in the mobile phase will reduce resolution and retention time of IRB. At the same time, the temperature of the column has a positive effect on $\mathrm{Sym}_{\mathrm{IRB}}$ and a negative effect on $\mathrm{Sym}_{\mathrm{HCT}}$. Since the selected responses were not affected in the same manner an additional optimization procedure was needed.

In order to get the best chromatographic performance, the multicriteria methodology was employed by means of Derringer's desirability function [22]. It is based on constructing desirable ranges for each response (individual desirable function, $\mathrm{d}_{\mathrm{i}}$ ) and establishing an overall desirability function (the Derringer desirability function). The Derringer's desirability function is defined as the geometric mean of individual desirability functions and can be expressed by Equation (2):

$$
\mathrm{D}=\left(\mathrm{d}^{\mathrm{p} 1}{ }_{1} \times \mathrm{d}^{\mathrm{p} 2}{ }_{2} \times \ldots . \mathrm{d}^{\mathrm{pn}}\right)^{1 / \mathrm{n}}
$$

where $\mathrm{n}$ is the number of responses, and $\mathrm{p}^{\mathrm{n}}$ is the weight of the responses. Weight of the response is the relative importance of each individual functions $d_{i}$ and may range from 0.1 to 10 . With a weight of 1 , $\mathrm{d}_{\mathrm{i}}$ varies in a linear way. In this study, weights equal to 1 was selected.

Individual desirability functions range from 0 (undesired response) to 1 (a fully desired response). A value of $\mathrm{D}$ close to 1 means that the combination of different criteria is globally optimal. If any of the responses or factors falls outside their desirability range, the overall function becomes zero. There are several ways for calculating the desirability function depending on the goal desired. The meanings of the goal parameters are:

\section{Maximum:}

$d_{i}=0$ if response $<$ low value; $0 \leq d_{i} \leq 1$ as response varies from low to high; $d_{i}=1$ if response $>$ high value

\section{Minimum:}

$d_{i}=1$ if response $<$ low value; $1 \geq d_{i} \geq 0$ as response varies from low to high; $d_{i}=0$ if response $>$ high value 


\section{Target:}

$d_{i}=0$ if response $<$ low value; $0 \leq d_{i} \leq 1$ as response varies from low to target; $1 \geq d_{i} \geq 0$ as response varies from target to high; $d_{i}=0$ if response $>$ high value

\section{Range:}

$d_{i}=0$ if response $<$ low value; $d_{i}=1$ as response varies from low to high; $d_{i}=0$ if response $>$ high value.

The goals of multicriteria optimization for each response in this paper are shown in Table 7.

Table 7. Criteria for multivariate optimization of the individual responses.

\begin{tabular}{cccccc}
\hline & Goal & Lower limit & Upper limit & Weight & Importance \\
\hline Percentage of methanol & In range & -1 & 1 & 1 & 3 \\
$\mathrm{pH}$ & In range & -1 & 1 & 1 & 3 \\
$\mathrm{~T}$ & In range & -1 & 1 & 1 & 3 \\
$\mathrm{k}_{\mathrm{R}}$ & Is target $=3$ & 2.52 & 27.56 & 1 & 3 \\
Sym IRB & In range & 0.97 & 1.52 & 1 & 1 \\
Sym HCT & In range & 1.2 & 1.53 & 1 & 1 \\
Rt IRB & Is target $=5$ & 2.605 & 14.567 & 1 & 5 \\
Rt HCT & In range & 2.258 & 2.867 & 1 & 5 \\
\hline
\end{tabular}

Desirability function calculations were performed using Design-Expert ${ }^{\circledR}$ 7.0. Obtained results are graphically presented (Figure 5).

Figure 5. Graphical representation of the constraints accepted fot the determination of global desirabilty and obtained optimal conditions.
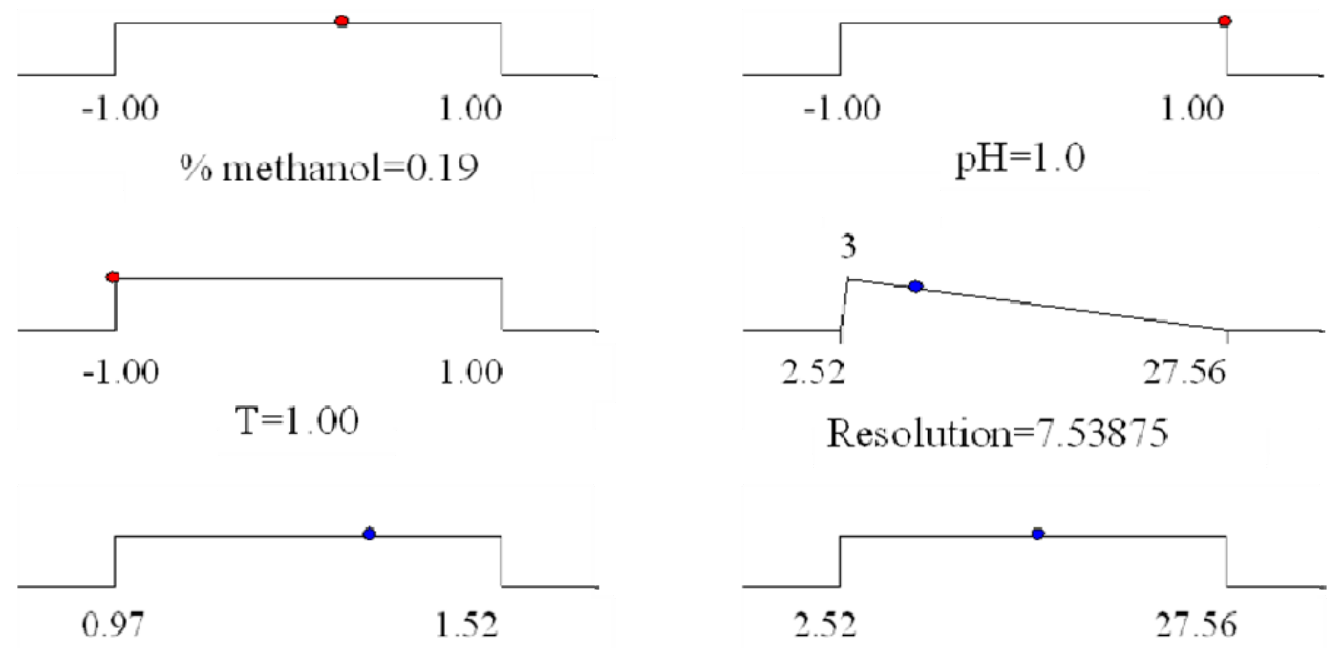

Sym IRB=1.33597

Sym HCT $=1.37095$
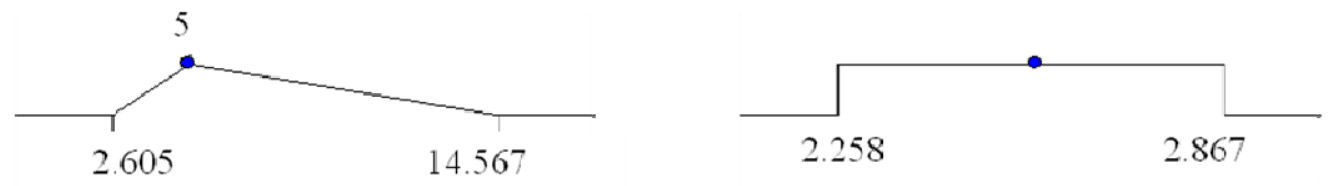

Rt IRB=4.99999

Rt HCT $=2.57197$

Desirability $=0.926$ 
For better visualization of the results, the global desirability function $\mathrm{D}$ was presented in a form of a three-dimensional plot and presented in Figure 6.

Figure 6. 3-D plots of the Derringer's desirability function in correlation with a variation of methanol content and $\mathrm{pH}(\mathbf{a})$, methanol content and temperature (b) and $\mathrm{pH}$ of mobile phase and temperature of column (c).

(a)

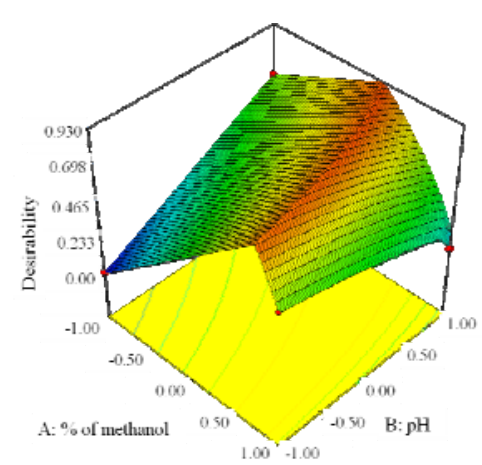

(b)

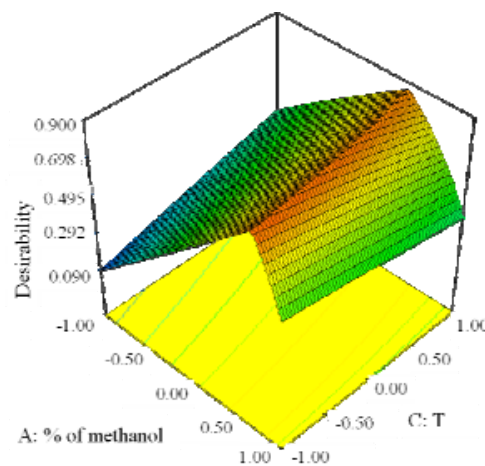

(c)

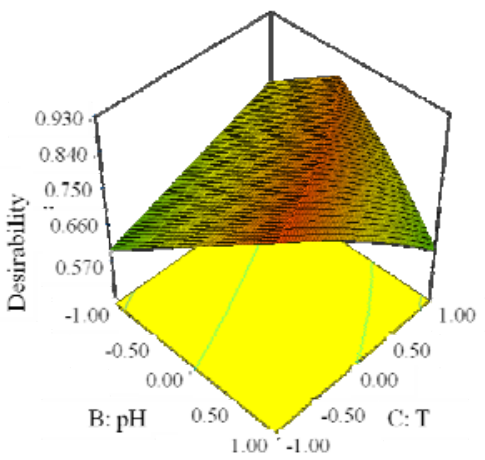

The coordinates related to the functions maximum are selected as the best operating conditions. The best chromatographic conditions are achieved with coded values of: $\%$ of methanol 0.19 , $\mathrm{pH}$ of mobile phase 1 and column's temperature -1 , i.e., with mobile phase methanol:tetrahydrofuran:acetate buffer from 47:10:43 v/v/v, pH 6.5 and column's temperature $25^{\circ} \mathrm{C}$. The representative chromatogram taken under these conditions is represented in Figure 7.

Figure 7. LC-PDA chromatogram of hydrochlorothiazide and irbesartan taken under optimized experimental conditions.

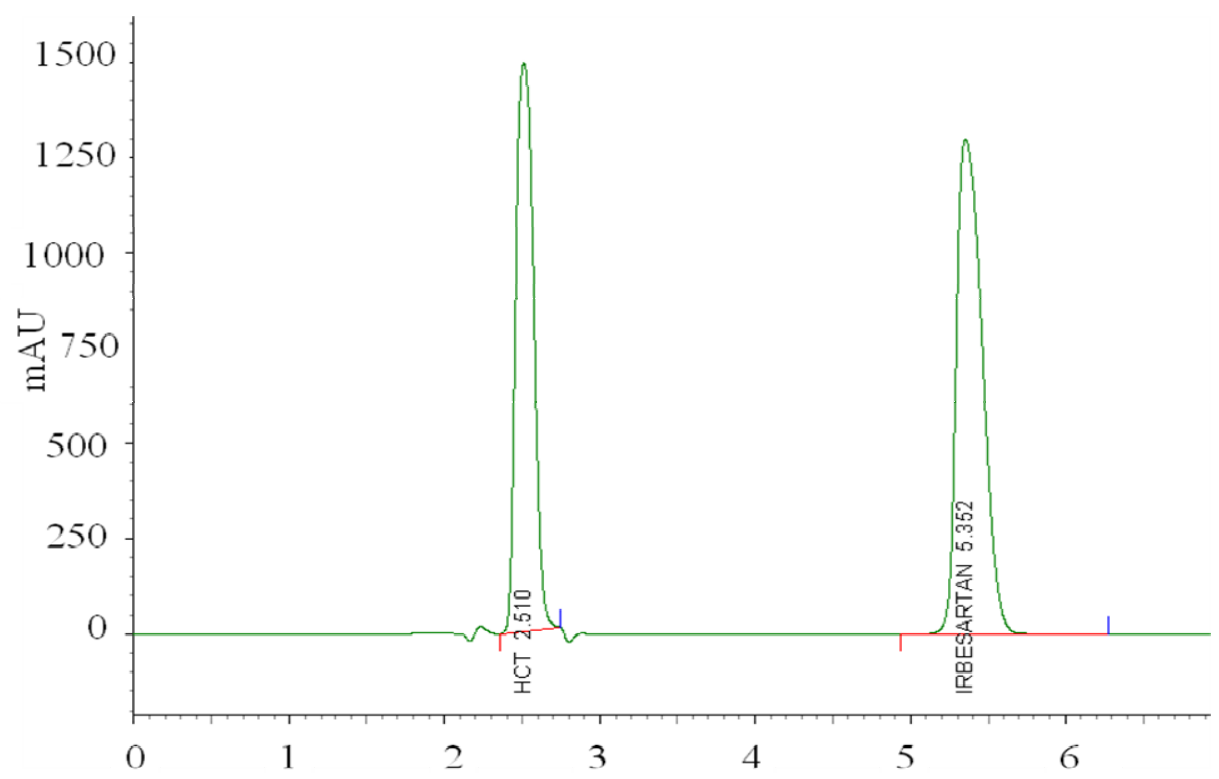

After setting the optimal conditions, the proposed method was validated. Interfering peaks were not detected at the retention time of IRB and HCT, indicating the good selectivity of the method. Linear dependence of the peak areas versus concentration was determined for the proposed ranges. 
Parameters of the linear regression equations were calculated and are presented in Table 8. The statistical significance of the intercept was tested using Student's t-test. The limit of detection (LOD) and limit of quantification (LOQ) were calculated as $\mathrm{LOD}=3 \sigma / \mathrm{S}$ and $\mathrm{LOQ}=10 \sigma / \mathrm{S}$, where $\sigma$ is the standard deviation of the response and $\mathrm{S}$ the intercept determined from the corresponding calibration curve.

Table 8. Statistical parameters for individual calibration curves.

\begin{tabular}{ccc}
\hline Parameter & IRB & HCT \\
\hline Concentration range $(\mathrm{mg} / \mathrm{mL})$ & $0.08-0.4$ & $0.02-0.1$ \\
Slope & 2.448 & 8.609 \\
Intercept & 0.035 & 0.0732 \\
$\mathrm{R}^{2}$ & 0.9976 & 0.9954 \\
$\mathrm{Sa}$ & 0.007 & 0.076 \\
$\mathrm{Sb}$ & 0.812 & 0.021 \\
$\mathrm{t} *$ & 1.872 & 1.256 \\
LOD & 0.02 & 0.006 \\
LOQ & 0.06 & 0.018 \\
\hline
\end{tabular}

Precision of the procedure was assessed by analyzing nine solutions containing known quantities of the investigated compounds. Law values of relative standard deviation for repeatability, RSD $<2.5 \%$, and high recovery (Table 9) indicate very good precision of the proposed method.

Table 9. Precision of the RP-HPLC method.

\begin{tabular}{cccc}
\hline Sample & Injected (mg/mL) & Found (mg/mL) & RSD (\%) \\
\hline Irbesartan & 0.120 & $121.29 \pm 0.13$ & 1.26 \\
& 0.160 & $160.09 \pm 0.15$ & 1.35 \\
& 0.190 & $191.75 \pm 0.21$ & 1.54 \\
Hydrochlorothiazide & 0.040 & $0.040 \pm 0.91$ & 0.44 \\
& 0.050 & $0.050 \pm 0.82$ & 0.53 \\
& 0.060 & $0.060 \pm 0.87$ & 0.59 \\
\hline
\end{tabular}

The applicability of the proposed method was examined by analysing commercially available Co-Irda tablets.

\section{Experimental}

\subsection{Drugs and Reagents}

The irbesartan and hydrochlorothiazide standards and Co-Irda tablets (Nobel Ilac, Istanbul, Turkey) consisting of $150 \mathrm{mg}$ IRB and HCT were obtained from Zada Pharmaceuticals d.o.o. (Tuzla, Bosnia and Herzegovina).

All solvents: methanol, tetrahydrofuran and sodium-acetate (purchased by Chromosol, Sigma-Aldrich, Munich, Germany), and acetic acid (Fluka, Eindhoven, The Netherlands) were of a grade suitable for high-performance liquid chromatography analysis. The HPLC analyses were done by using a Thermo Finnigan Surveyor chromatographic system equipped with a PDA detector and sample injections were 
made through an injector valve with a $5 \mu \mathrm{L}$ sample loop. Separations were performed on a Supelcosil $\mathrm{C}_{18}$ column $(150 \mathrm{~mm} \times 4.6 \mathrm{~mm}, 5 \mu \mathrm{m}$ particle size $)$ with detection at $271 \mathrm{~nm}$. Mobile phases were prepared according to the plan of the experiments given in Table 4. The resulting mobile phases were degassed and vacuum filtered through a $0.45 \mu \mathrm{m}$ membranes filter (Alltech Associates, Lokeren, Belgium). The flow rate was $0.75 \mathrm{~mL} / \mathrm{min}$.

\subsection{Software}

Experimental design, statistical analysis and desirabiity function calculation were performed by using MarvinSketch 5.8.2 (Chem Axon Ltd., Somerville, MA, USA, and Budapest, Hungary) and Design-Expert ${ }^{\circledR} 7.0$ (Stat-Ease Inc.).

\subsection{Solutions}

Stock solutions were prepared by dissolving standard substances in methanol to obtain concentrations of $0.8 \mathrm{mg} / \mathrm{mL}$ for IRB and $0.2 \mathrm{mg} / \mathrm{mL}$ for IRB.

\subsubsection{Solutions for Method Optimization}

Stock solutions were diluted with methanol to obtain a concentration of $0.08 \mathrm{mg} / \mathrm{mL}$ of IRB and $0.02 \mathrm{mg} / \mathrm{mL}$ of HCT.

\subsubsection{Standard Solutions for Linearity Testing}

For the calibration curves, a series of eight solutions were prepared from stock solution in the concentration range from 0.08 to $0.4 \mathrm{mg} / \mathrm{mL}$ for IRB and from 0.02 to $0.1 \mathrm{mg} / \mathrm{mL}$ for HCT.

\subsubsection{Solutions for Accuracy Testing}

The laboratory mixture containing placebo, IRB and HCT was prepared in the ratio related to the investigated tablets. For the quantiative analysis, three solutions corresponding to $80 \%, 100 \%$ and $120 \%$ to those in tablets were prepared.

\subsubsection{Solutions for Estimating Precision}

In order to estimate precision, three series $(0.16,0.24$ and $0.32 \mathrm{mg} / \mathrm{mL}$ for IRB; $0.04,0.06$ and $0.08 \mathrm{mg} / \mathrm{mL}$ for HCT) were prepare with ten solutions for each of the concentrations.

\subsubsection{Sample Solutions}

A tablet mass which corresponds to $150 \mathrm{mg}$ IRB and $12.5 \mathrm{mg} \mathrm{HCT}$ was dissolved in $100 \mathrm{~mL}$ volumetric flask with methanol, placed into a ultrasonic bath and filtrated. $2 \mathrm{~mL}$ of filtrate were diluted with methanol to $10 \mathrm{~mL}$. 


\section{Conclusions}

Experimental design methodology was used for simultaneous HPLC determination of irbesartan and hydrochlorothiazide in combined dosage forms. The significant feature of these combinations lies in the fact that hydrochlorothiazide is present in minute amounts compared to irbesartan which makes for a more complicated and tedious analysis.

The chemometric approach for optimization of chromatographic separation of irbesartan and hydrochlorothiazide has been demonstrated. The chemometric methodology chosen for the particular objectives was very successful in the retention behavior exploration. Since there was a mix of linear responses with different targets, Derringer's desirability function was applied. After defining a global desirability according to the accepted constraints, optimal chromatographic conditions were established.

The proposed HPLC method was validated according to ICH guidelines. From the study of validation parameters, it was observed that the method is specific, accurate, precise, reproducible and is not time-consuming (run time is less than six minutes). Since there was no interference from other components present in the dosage forms, complicated procedures for extraction were not required. The results obtained in this study corroborate that the proposed HPLC method can be used for routine quantitative analyses of the investigated compounds in a mixture or for their individual determination in pharmaceutical dosage forms.

\section{Acknowledgment}

We gratefully acknowledge the financial support from the Ministry of Science and Environment of the Republic of Serbia, grants OI 172041 and TR 34031.

\section{References and Notes}

1. Burnier, M.; Brunner, H.R. Angiotensin II receptor antagonists. Lancet 2000, 355, 637-645.

2. Rosangluaia; Shanmugasundaram, P.; Malarkodi, V. Validated HPTLC method for simultaneous estimation of irbesartan and hydrochlorthiazide in a tablet dosage form. Der Pharm. Chem. 2011, 3, 310-317.

3. Shah, N.J.; Suhagia, B.N.; Shah, R.R.; Patel, N.M. Development and validation of a HPTLC method for the simultaneous estimation of irbesartan and hydrochlorothiazide in tablet dosage form. Indian J. Pharm. Sci. 2007, 69, 240-243.

4. Amol, S.K.; Laxman, V.P.; Mrinalini, C.D.; Kailash, G.B. A validated stability indicating HPTLC method for simultaneous estimation of irbesartan and hydrochlorothiazide. Pharm. Methods 2010, $1,39-43$.

5. Mehta, B.H.; Morge, S.B. Simultaneous determination of irbesartan and hydrochlorothiazide by HPTLC method. Indian Drugs 2010, 47, 71-74.

6. Patel, K.R.; Patel, S.A.; Darji, V.C.; Sonpal, R.N. Simultaneous spectrophotometric determination of irbesartan and hydrochlorothiazide in tablets. Int. Res. J. Pharm. 2011, 2, 202-207.

7. Farouk, M.; Abd ElAziz, O.; Hemdan, A.; Shehata, M. Spectrofluorimetric methods for determination of some anti-hypertensive drugs. J. Am. Sci. 2011, 7, 300-312. 
8. Ramzia, I.E.-B.; Hanaa, M.H.; Waleed, A.E. Spectrofluorometric, spectrophotometric and LC determination of irbesartan. J. Chem. Pharm. Res. 2011, 3, 722-733.

9. Burçin, B.; Burcu, D.T.; Bengi, U.; Sibel, A.Ö.; Hassan, Y.A.-E. Quantitative analysis of irbesartan in pharmaceuticals and human biological fluids by voltammetry. Anal. Lett. 2009, 42, 2322-2338.

10. Hillaert, S.; van den Bossche, W. Simultaneous determination of hydrochlorothiazide and several angiotensin-II-receptor antagonists by capillary electrophoresis. J. Pharm. Biomed. Anal. 2003, 31, 329-339.

11. Farouk, M.; Abd ELAziz, O.; Hemdan, A.; Shehata, M. Novel validated chromatographic method for determination of some anti-hypertensive drugs. J. Am. Sci. 2010, 6, 476-486.

12. Gonzalez, L.; Lopez, J.A.; Alonso, R.M.; Jimenez, R.M. Fast screening method for the determination of angiotensin II receptor antagonists in human plasma by high-performance liquid chromatography with fluorimetric detection. J. Chromatogr. A 2002, 949, 49-60.

13. Ganesan, M.; Nanjundan, S.; Gomathi, M.; Muralidharan, S. Method development and validation of Irbesartan using LCMS/MS: Application to pharmacokinetic studies. J. Chem. Pharm. Res. 2010, 2, 740-746.

14. Tutunji, L.F.; Tutunji, M.F.; Alzoubi, M.I.; Khabbas, M.H.; Arida, A.I. Simultaneous determination of irbesartan and hydrochlorothiazide in human plasma using HPLC coupled with tandem mass spectroscopy, application to bioeqivalance study. J. Pharm. Biomed. Anal. 2010, 51, 985-990.

15. Hillaert, S.; Van den Bossche, W. Optimization and validation of a capillary zone electrophoretic method for the analysis of several angiotensin-II-receptor antagonists. J. Chromatogr. A 2002, 979, 323-333.

16. Hillaert, S.; de Beer, T.R.M.; de Beer, J.O.; van den Bossche, W. Optimization and validation of a micellar electrokinetic chromatographic method for the analysis of several angiotensin-II-receptor antagonists. J. Chromatogr. A 2003, 984, 135-146.

17. Ferreirós, N.; Iriarte, G.; Alonso, R.M.; Jiménez, R.M. MultiSimplex and experimental design as chemometric tools to optimize a SPE-HPLC-UV method for the determination of eprosartan in human plasma samples. Talanta 2006, 69, 747-756.

18. Torrealdaya, N.; Gonzáleza, L.; Alonso, R.M.; Jiméneza, R.M.; Ortiz Lastra, E. Experimental design approach for the optimisation of a HPLC-fluorimetric method for the quantitation of the angiotensin II receptor antagonist telmisartan in urine. J. Pharm. Biomed. Anal. 2003, 32, 847-857.

19. Gotardo, M.A.; Pezza, L.; Pezza, H.R. Determination of hydrochlorothiazide in pharmaceutical formulations by diffuse reflectance spectroscopy. Eclet. Quim. 2005, 30, 17-24.

20. Silva Sangoi, M.; Wrasse-Sangoi, M.; Renato de Oliveira, P.; Todeschini Clarice, V.; Bueno Rolim, M. Rapid simultaneous determination of aliskiren and hydrochlorothiazide from their pharmaceutical formulations bz monolithic silica HPLC column employing experimental design. J. Liq. Chromatogr. Relat. Technol. 2011, 34, 1976-1996.

21. Demiralaya, E.C.; Cubuka, B.; Ozkanb, S.A.; Alsancaka, G. Combined effect of polarity and pH on the chromatographic behavior of some angiotensin II receptor antagonists and optimization of their determination in pharmaceutical dosage forms. J. Pharm. Biomed. Anal. 2010, 53, 475-482. 
22. Jocić, B.; Zecević, M.; Zivanović, L.J.; Protić, A.; Jadranin, M.; Vajs, V. Study of forced degradation behavior of eletriptan hydrobromide by LC and LC-MS and development of stability-indicating method. J. Pharm. Biomed. Anal. 2008, 46, 622-629.

Sample Availability: Not available.

(C) 2012 by the authors; licensee MDPI, Basel, Switzerland. This article is an open access article distributed under the terms and conditions of the Creative Commons Attribution license (http://creativecommons.org/licenses/by/3.0/). 